\title{
Analysis of Wavelength-Dependent Performance Variations of GaN-Based Ultraviolet Lasers
}

\author{
Joachim Piprek, ${ }^{\text {i }}$ Hans Wenzel, ${ }^{2}$ and Michael Kneissl ${ }^{3,2}$ \\ NUSOD Institute, Newark, DE 19714-7204 \\ ${ }^{2}$ Ferdinand-Braun-Institut für Höchstfrequenztechnik, Kirchhoff Str. 4, 12489 Berlin, Germany \\ ${ }^{3}$ Technical University of Berlin, Hardenbergstr. 36, 10623 Berlin, Germany
}

\begin{abstract}
We analyze the performance of a set of gallium nitride based laser diodes emitting ultraviolet light between $360 \mathrm{~nm}$ and $380 \mathrm{~nm}$ wavelength. The wavelength variation was accomplished by varying the indium content of the InGaN quantum wells which are embedded in AlInGaN barriers. The experiments revealed a strong increase in threshold current with shorter wavelength. Our analysis utilizes advanced numerical laser simulation. Novel models for quaternary AlInGaN material properties are developed and result in good agreement between simulation and measurements. The measured rise in threshold current with shorter wavelength is found to have two main reasons. The first reason is the increased absorption of UV light inside the laser, mainly within p-doped layers. The second mechanism contributing to the performance deterioration is the leakage of carriers from the active region. In particular, the hole leakage is found to strongly increase with lower indium mole fraction of the quantum well (shorter wavelength), due to the reduced valence band offset.
\end{abstract}

Keywords: GaN-based laser diode, ultraviolet light emitter, numerical device simulation

\section{INTRODUCTION}

The cutting edge in semiconductor light sources has moved into the ultraviolet (UV). One important application of semiconductor UV optical sources will be for compact and sensitive bioagent detection systems for airborne pathogens like Anthrax spores. Other potential applications of UV light emitters include sterilization and disinfectant devices, UV curing, solid-state lighting, and compact analytical devices for the biotechnology and pharmaceutical markets.

We analyze the performance of a set of UV laser diodes emitting between $360 \mathrm{~nm}$ and $380 \mathrm{~nm}$ wavelength. ${ }^{1}$ The devices were grown on c-plane sapphire substrates by metalorganic chemical vapor deposition. The epitaxial layer sequence is listed in Table 1. InGaN quantum wells and InAlGaN barriers form the multi-quantum-well (MQW) active region. Lowering the indium mole fraction in the InGaN quantum well results in a reduction of the emission wavelength. However, a dramatic increase of the threshold current was measured with shorter wavelength.

Our paper investigates the reasons for this performance deterioration using advanced laser simulation software. ${ }^{2}$ The simulation combines a semiconductor transport model with quantum well (QW) gain calculation and optical waveguiding. The transport model includes built-in fields due to spontaneous and piezoelectric polarization as well as thermionic emission at hetero-interfaces. The QW gain calculation considers the wurtzite band structure, strain, bandgap renormalization, and the quantum-confined Stark effect. Further details on the model and equations are given elsewhere. ${ }^{3}$ Heat flux calculations are not included in our analysis of pulsed laser operation.

\footnotetext{
${ }^{\text {i } C o r r e s p o n d i n g ~ a u t h o r, ~ e-m a i l: ~ p i p r e k @ n u s o d . o r g ~}$
} 


\begin{tabular}{|c|c|c|c|c|}
\hline $\begin{array}{l}\text { LAYER } \\
\text { DESCRIPTION }\end{array}$ & MATERIAL COMPOSITION & THICKNESS & $\begin{array}{l}\text { CARRIER } \\
\text { DENSITY }\end{array}$ & $\begin{array}{l}\text { REFRACTIVE } \\
\text { INDEX }\end{array}$ \\
\hline & & $\mathrm{nm}$ & $\mathrm{cm}^{-3}$ & $(370 \mathrm{~nm})$ \\
\hline contact & GaN & 20.0 & $\mathrm{p}=2 \mathrm{E} 18$ & 2.703 \\
\hline SL cladding & $\mathrm{Al}(0.12) \mathrm{GaN}$ & 500.0 & $\mathrm{p}=1 \mathrm{E} 18$ & 2.554 \\
\hline waveguide & $\mathrm{Al}(0.06) \mathrm{GaN}$ & 100.0 & $\mathrm{p}=5 \mathrm{E} 17$ & 2.611 \\
\hline stopper & $\mathrm{Al}(0.3) \mathrm{GaN}$ & 20.0 & $\mathrm{p}=1 \mathrm{E} 18$ & 2.44 \\
\hline barrier & $\mathrm{In}(0.01) \mathrm{Al}(0.16) \mathrm{Ga}(0.83) \mathrm{N}$ & 7.0 & uid & 2.56 \\
\hline well & $\mathrm{In}(0.02) \mathrm{GaN}$ & 3.5 & uid & 2.749 \\
\hline barrier & $\mathrm{In}(0.01) \mathrm{Al}(0.16) \mathrm{Ga}(0.83) \mathrm{N}$ & 2.7 & uid & 2.56 \\
\hline barrier & $\mathrm{In}(0.01) \mathrm{Al}(0.16) \mathrm{Ga}(0.83) \mathrm{N}$ & 1.6 & $\mathrm{n}=5 \mathrm{E} 18$ & 2.56 \\
\hline barrier & $\mathrm{In}(0.01) \mathrm{Al}(0.16) \mathrm{Ga}(0.83) \mathrm{N}$ & 2.7 & uid & 2.56 \\
\hline well & $\mathrm{In}(0.02) \mathrm{GaN}$ & 3.5 & uid & 2.749 \\
\hline barrier & $\mathrm{In}(0.01) \mathrm{Al}(0.16) \mathrm{Ga}(0.83) \mathrm{N}$ & 2.7 & uid & 2.56 \\
\hline barrier & $\mathrm{In}(0.01) \mathrm{Al}(0.16) \mathrm{Ga}(0.83) \mathrm{N}$ & 1.6 & $\mathrm{n}=5 \mathrm{E} 18$ & 2.56 \\
\hline barrier & $\mathrm{In}(0.01) \mathrm{Al}(0.16) \mathrm{Ga}(0.83) \mathrm{N}$ & 2.7 & uid & 2.56 \\
\hline well & $\mathrm{In}(0.02) \mathrm{GaN}$ & 3.5 & uid & 2.749 \\
\hline barrier & $\mathrm{In}(0.01) \mathrm{Al}(0.16) \mathrm{Ga}(0.83) \mathrm{N}$ & 2.7 & uid & 2.56 \\
\hline barrier & $\mathrm{In}(0.01) \mathrm{Al}(0.16) \mathrm{Ga}(0.83) \mathrm{N}$ & 1.6 & $\mathrm{n}=5 \mathrm{E} 18$ & 2.56 \\
\hline barrier & $\mathrm{In}(0.01) \mathrm{Al}(0.16) \mathrm{Ga}(0.83) \mathrm{N}$ & 2.7 & uid & 2.56 \\
\hline well & $\mathrm{In}(0.02) \mathrm{GaN}$ & 3.5 & uid & 2.749 \\
\hline barrier & $\mathrm{In}(0.01) \mathrm{Al}(0.16) \mathrm{Ga}(0.83) \mathrm{N}$ & 2.7 & uid & 2.56 \\
\hline barrier & $\mathrm{In}(0.01) \mathrm{Al}(0.16) \mathrm{Ga}(0.83) \mathrm{N}$ & 1.6 & $\mathrm{n}=5 \mathrm{E} 18$ & 2.56 \\
\hline barrier & $\mathrm{In}(0.01) \mathrm{Al}(0.16) \mathrm{Ga}(0.83) \mathrm{N}$ & 2.7 & uid & 2.56 \\
\hline well & $\mathrm{In}(0.002-0.027) \mathrm{GaN}$ & 3.5 & uid & 2.749 \\
\hline barrier & $\operatorname{In}(0.02) \mathrm{GaN}$ & 7.0 & uid & 2.56 \\
\hline waveguide & $\mathrm{Al}(0.06) \mathrm{GaN}$ & 100.0 & $\mathrm{n}=1 \mathrm{E} 17$ & 2.611 \\
\hline SL cladding & $\mathrm{Al}(0.12) \mathrm{GaN}$ & 800.0 & $\mathrm{n}=1 \mathrm{eE} 18$ & 2.554 \\
\hline compliance & $\mathrm{In}(0.02) \mathrm{GaN}$ & 100.0 & $\mathrm{n}=5 \mathrm{E} 18$ & 2.822 \\
\hline current spreading & $\mathrm{GaN}$ & 4000.0 & $\mathrm{n}=5 \mathrm{E} 18$ & 2.703 \\
\hline
\end{tabular}

Tab. 1 Epitaxial layer sequence of the UV laser (SL - superlattice with average properties, uid - unintentional doping).

\section{MATERIAL PROPERTIES}

Our drift-diffusion model of carrier transport includes Fermi statistics and thermionic emission at hetero-interfaces. Thermionic emission is mainly controlled by the offset of conduction band $\left(\Delta \mathrm{E}_{\mathrm{c}}\right)$ and valence band $\left(\Delta \mathrm{E}_{\mathrm{v}}\right)$ at heterobarriers. We here use a band offset ratio $\left(\Delta \mathrm{E}_{\mathrm{c}} / \Delta \mathrm{E}_{\mathrm{v}}\right)$ of $70 / 30$ for all interfaces, which corresponds to an average of reported values. ${ }^{4}$ The room temperature band gap $E_{g}$ of ternary and quaternary layers is calculated from the nonlinear interpolation formula $(\mathrm{z}=1-\mathrm{x}-\mathrm{y})$

$E_{g}\left(A_{x} I_{y} G_{2} N\right)=x E_{A l N}+y E_{I n N}+z E_{G a N}+x y b_{A I I n N}+y z b_{I n G a N}+x z b_{A l G a N}+x y z b_{A I I n G a N}$ 
with the binary bandgaps $\mathrm{E}_{\mathrm{AlN}}=6.28 \mathrm{eV}, \mathrm{E}_{\mathrm{InN}}=0.77 \mathrm{eV}$, and $\mathrm{E}_{\mathrm{GaN}}=3.42 \mathrm{eV}$. The ternary bowing parameters are $\mathrm{b}_{\mathrm{AIInN}}=-3.4 \mathrm{eV}, \mathrm{b}_{\text {InGaN }}=-1.43 \mathrm{eV}$, and $\mathrm{b}_{\mathrm{AlGaN}}=-0.7 \mathrm{eV}$. The quaternary bowing parameter $\mathrm{b}_{\mathrm{AIInGaN}}$ may be used to fit bandgap measurements, which are currently unavailable for quaternary layers $\left(\mathrm{b}_{\mathrm{AlInGaN}}=0\right)$.

The Shockley-Read-Hall (SRH) recombination lifetime of electrons and holes is assumed to be $5 \mathrm{~ns}$ in all layers, the actual numbers for our device are unknown. The SRH lifetime controls the non-radiative recombination since the small GaN Auger parameter of $\mathrm{C}=10^{-34} \mathrm{~cm}^{6} / \mathrm{s}$ makes Auger recombination irrelevant. Within passive layers, a spontaneous emission parameter of $\mathrm{B}=5 \times 10^{-11} \mathrm{~cm}^{3} \mathrm{~s}^{-1}$ is employed. The spontaneous recombination rate in quantum wells is much larger than in passive layers and it is calculated self-consistently together with the quantum well gain. Both are affected by the built-in quantum well field due to spontaneous and piezoelectric polarization. We here employ the recently updated polarization model by Bernardini which uses interpolation formulas like (1) for quaternary layers. ${ }^{5}$ The resulting density of fixed polarization charges is given in Table 2 for different hetero-interfaces. It slightly decreases for lower QW indium content (shorter wavelength). However, the theoretical polarization charge density may be reduced in practice, e.g., by charged interface defects. We therefore use only half the values in Table 2 for this investigation.

\begin{tabular}{|l|l|}
\hline Interface & Charge Density \\
\hline $\mathrm{GaN} / \mathrm{Al}_{0.12} \mathrm{Ga}_{0.88} \mathrm{~N}$ & $\pm 5.02 \times 10^{12} \mathrm{~cm}^{-2}$ \\
\hline $\mathrm{Al}_{0.12} \mathrm{Ga}_{0.88} \mathrm{~N} / \mathrm{Al}_{0.06} \mathrm{Ga}_{0.94} \mathrm{~N}$ & $\pm 2.60 \times 10^{12} \mathrm{~cm}^{-2}$ \\
\hline $\mathrm{Al}_{0.30} \mathrm{Ga}_{0.70} \mathrm{~N} / \mathrm{Al}_{0.06} \mathrm{Ga}_{0.94} \mathrm{~N}$ & $\pm 11.6 \times 10^{12} \mathrm{~cm}^{-2}$ \\
\hline $\mathrm{Al}_{0.30} \mathrm{Ga}_{0.70} \mathrm{~N} / \mathrm{Al}_{0.16} \mathrm{In}_{0.01} \mathrm{Ga}_{0.83} \mathrm{~N}$ & $\pm 8.11 \times 10^{12} \mathrm{~cm}^{-2}$ \\
\hline $\mathrm{Al}_{0.06} \mathrm{Ga}_{0.94} \mathrm{~N} / \mathrm{Al}_{0.16} \mathrm{In}_{0.01} \mathrm{Ga}_{0.83} \mathrm{~N}$ & $\pm 3.48 \times 10^{12} \mathrm{~cm}^{-2}$ \\
\hline $\mathrm{In}_{0.005} \mathrm{Ga}_{0.995} \mathrm{~N} / \mathrm{Al}_{0.16} \mathrm{In}_{0.01} \mathrm{Ga}_{0.83} \mathrm{~N}$ & $\pm 6.34 \times 10^{12} \mathrm{~cm}^{-2}$ \\
\hline $\mathrm{In}_{0.010} \mathrm{Ga}_{0.990} \mathrm{~N} / \mathrm{Al}_{0.16} \mathrm{In}_{0.01} \mathrm{Ga}_{0.83} \mathrm{~N}$ & $\pm 6.79 \times 10^{12} \mathrm{~cm}^{-2}$ \\
\hline $\mathrm{In}_{0.015} \mathrm{Ga}_{0.985} \mathrm{~N} / \mathrm{Al}_{0.16} \mathrm{In}_{0.01} \mathrm{Ga}_{0.83} \mathrm{~N}$ & $\pm 7.24 \times 10^{12} \mathrm{~cm}^{-2}$ \\
\hline $\mathrm{In}_{0.020} \mathrm{Ga}_{0.980} \mathrm{~N} / \mathrm{Al}_{0.16} \mathrm{In}_{0.01} \mathrm{Ga}_{0.83} \mathrm{~N}$ & $\pm 7.70 \times 10^{12} \mathrm{~cm}^{-2}$ \\
\hline $\mathrm{In}_{0.025} \mathrm{Ga}_{0.975} \mathrm{~N} / \mathrm{Al}_{0.16} \mathrm{In}_{0.01} \mathrm{Ga}_{0.83} \mathrm{~N}$ & $\pm 8.16 \times 10^{12} \mathrm{~cm}^{-2}$ \\
\hline $\mathrm{In}_{0.030} \mathrm{Ga}_{0.970} \mathrm{~N} / \mathrm{Al}_{0.16} \mathrm{In}_{0.01} \mathrm{Ga}_{0.83} \mathrm{~N}$ & $\pm 8.63 \times 10^{12} \mathrm{~cm}^{-2}$ \\
\hline $\mathrm{In}_{0.02} \mathrm{Ga}_{0.98} \mathrm{~N} / \mathrm{Al}_{0.12} \mathrm{Ga}_{0.88} \mathrm{~N}$ & $\pm 6.82 \times 10^{12} \mathrm{~cm}^{-2}$ \\
\hline $\mathrm{In}_{0.02} \mathrm{Ga}_{0.98} \mathrm{~N} / \mathrm{GaN}$ & $\pm 1.80 \times 10^{12} \mathrm{~cm}^{-2}$ \\
\hline
\end{tabular}

Table 2: Fixed polarization charge densities for different types of interfaces, the sign depends on the growth direction.

To model our strained InGaN/AlInGaN quantum wells, the conduction bands are assumed to be parabolic and the nonparabolic valence bands are computed by the $6 \times 6$ kp method. ${ }^{6}$ We use the recommended values of Vurgaftman and Meyer for the binary bandstructure parameters. ${ }^{4}$ Ternary and quaternary parameters are obtained by linear interpolation. For gain computation, a free-carrier model is utilized with Lorentz broadening and an empirical intraband scattering time of $33 \mathrm{fs}$. Band gap shrinkage caused by carrier-carrier interaction is considered as $\Delta \mathrm{E}_{\mathrm{g}}=-\xi \mathrm{C}^{1 / 3}$ with the average free carrier density $\mathrm{C}$ and the renormalization parameter $\xi=3 \times 10^{-8} \mathrm{eVcm}$. The built-in polarization field in the quantum well is considered self-consistently, resulting an a longer emission wavelength, a reduced overlap of electron and hole wavefunction, and in reduced photon emission.

However, the most critical parameter in this investigation is the absorption coefficient of ternary and quaternary nitride alloys. Only few absorption measurements are reported for nitrides, mostly for GaN. Early experimental investigations result in large absorption coefficients, probably due to poor material quality. ${ }^{7,8}$ More recently, Kuramoto et al. measured the effect of GaN doping for photon energies right below the bandgap. ${ }^{9}$ The measured absorption is attributed to crystal defects caused by doping which result in band tails with two characteristic regions. We model this band-tail absorption as function of photon energy hv using

$$
\alpha(x, y)=a_{1}(N, P) \exp \left[\frac{h v-E_{g}(x, y)}{b_{1}(N, P)}\right]+a_{2}(N, P) \exp \left[\frac{h v-E_{g}(x, y)}{b_{2}(N, P)}\right]
$$


and obtaining good agreement with the measurements (Fig. 1). The first term in (3) represents the short-wavelength region and the second term the long-wavelength region of the measured spectra. The fit parameters a and $\mathrm{b}$ include the influence of doping densities $\mathrm{N}$ and $\mathrm{P}$ for $\mathrm{Si}$ and $\mathrm{Mg}$ dopants, respectively,

$$
\begin{array}{ll}
\mathrm{a}_{1}\left[\mathrm{~cm}^{-1}\right]=19000+4000 \mathrm{~N}+200 \mathrm{P}, & \mathrm{a}_{2}\left[\mathrm{~cm}^{-1}\right]=330+200 \mathrm{~N}+30 \mathrm{P}, \\
\mathrm{b}_{1}[\mathrm{eV}]=0.019+0.001 \mathrm{~N}+0.0001 \mathrm{P}, & \mathrm{b}_{2}[\mathrm{eV}]=0.07+0.016 \mathrm{~N}+0.0008 \mathrm{P} .
\end{array}
$$

Using the bandgap formula (1), the band-tail absorption can be calculated for arbitrary AlInGaN compositions by simply moving the spectrum along with the bandgap energy.

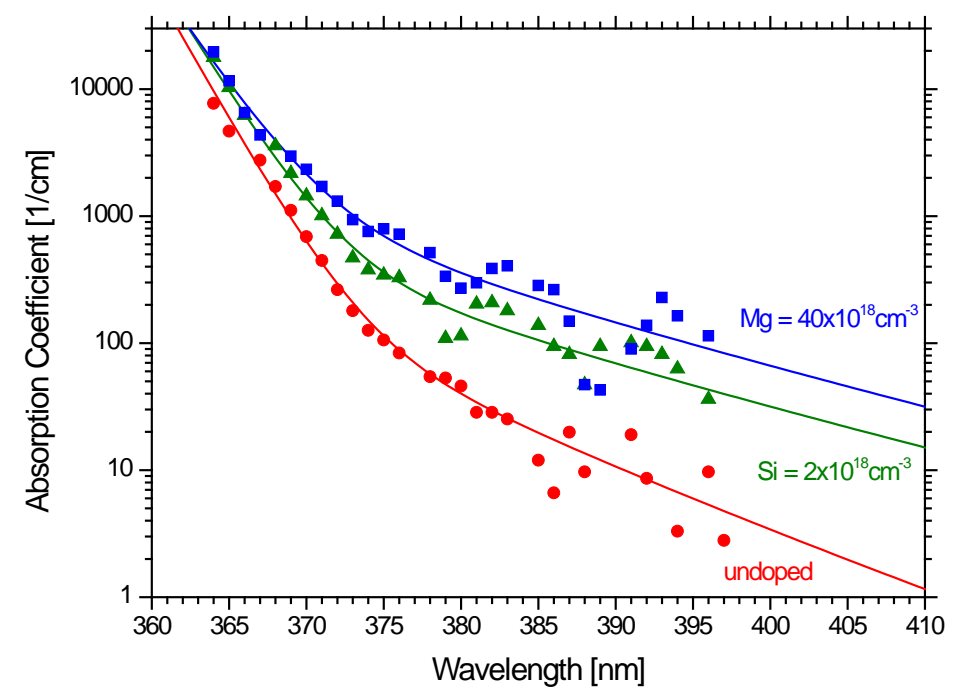

Fig. 1: GaN absorption spectrum for photon energies below the bandgap (363 nm) and different doping. Dots - measurements, ${ }^{9}$ lines - equation (3).

The refractive index of quaternary materials is calculated using ${ }^{10}$

$$
n(x, y)=\operatorname{Re}\left[B(x, y)+\frac{A(x, y)}{\pi} \ln \left(\frac{E_{1}(x, y)^{2}-E^{2}}{E_{g}(x, y)^{2}-E^{2}}\right)+\frac{G(x, y)}{E_{1}(x, y)^{2}-E^{2}}\right]
$$

where $\mathrm{E}=\mathrm{h} v+\mathrm{i} \gamma$ is the complex photon energy $(\gamma=25 \mathrm{meV})$ and $\mathrm{A}, \mathrm{B}, \mathrm{E}_{1}$, and $\mathrm{G}$ are empirical parameters obtained from fits to measurements ${ }^{11}$ with interpolation formulas like (1). The resulting refractive index for $370 \mathrm{~nm}$ wavelength is listed in Table 1 and the vertical refractive index profile is plotted in Fig. 2.

\section{RESULTS AND ANALYSIS}

We first evaluate the results for InGaN quantum wells with $2 \%$ Indium which give an emission close to the middle of the investigated wavelength range. The first set of figures illustrates internal optical properties in the center of the laser. The vertical refractive index profile is shown in Fig. 2 and the absorption profile in Fig. 3, indicating strong absorption in the p-doped layers. The optical mode profile in Fig. 4 is somewhat distorted by the low index of the stopper layer, the 
optical confinement factor is 0.05 . The mode penetrates deeply into the high-absorption region, resulting in a high modal absorption coefficient of $120 \mathrm{~cm}^{-1}$. Figure 5 shows a non-uniform spontaneous emission of the quantum wells and it also reveals emission from the n-side waveguide layer, indicating hole leakage.

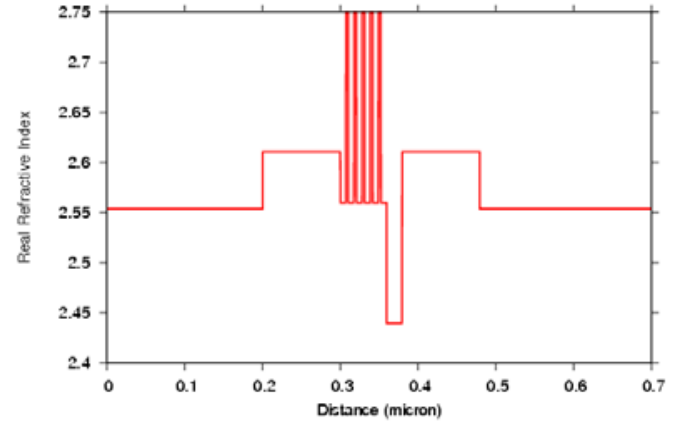

Fig. 2: Vertical refractive index profile near the MQW.

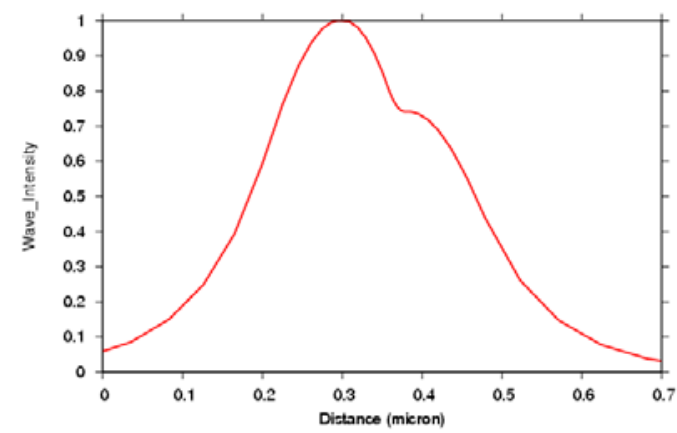

Fig. 4: Vertical profile of the optical mode.

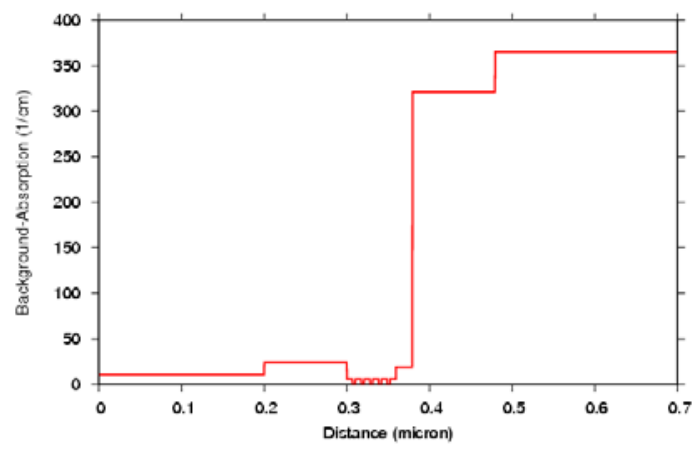

Fig. 3: Vertical absorption profile near the MQW.

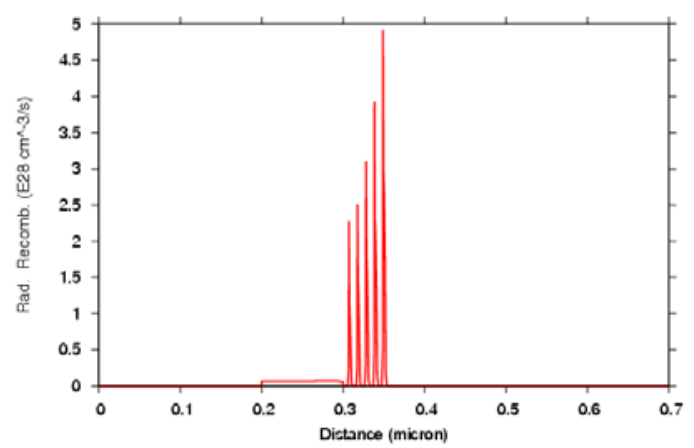

Fig. 5: Vertical profile of the spontaneous recombination rate.

The next set of profiles illustrates the electronic properties of the device at a high current density of $25 \mathrm{kA} / \mathrm{cm}^{2}$ that is chosen well above the highest threshold current density measured. Figure 6 gives the energy band diagram showing the strong QW deformation due to the polarization charges which are not completely screened by QW carriers, even at high current. The carrier density profiles are plotted in Figs. 7 and 8. As expected for GaN-based lasers, the QW carrier density is well above $10^{19} \mathrm{~cm}^{-3}$. It is slightly higher in the p-side quantum wells but there is also a relevant accumulation of both electrons and holes in the n-side waveguide layer which has a lower bandgap than the surrounding layers. This carrier accumulation feeds the waveguide emission in Fig. 5 and it also causes relevant SRH recombination in the nwaveguide (Fig. 9). Overall, due to the relatively long lifetime chosen, the SRH recombination is much smaller than the spontaneous recombination. Figures 10 and 11 give the current density profiles. Due to the high energy barrier of the stopper layer, the electron leakage into the p-region is relatively small, less than $2 \%$ of the total current (Fig. 10). The clearly stronger hole leakage into the n-waveguide amounts to $8 \%$ of the total current (Fig. 11). 


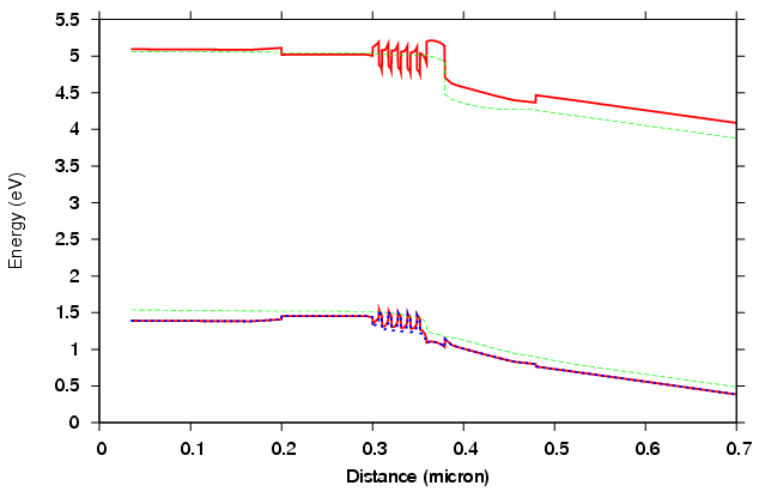

Fig. 6: Energy band diagram (dotted - quasi Fermi levels).

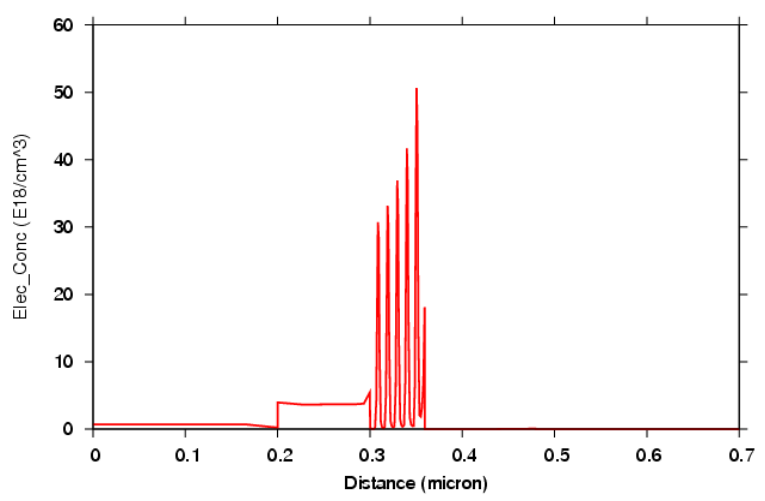

Fig. 8: Vertical profile of the electron density.

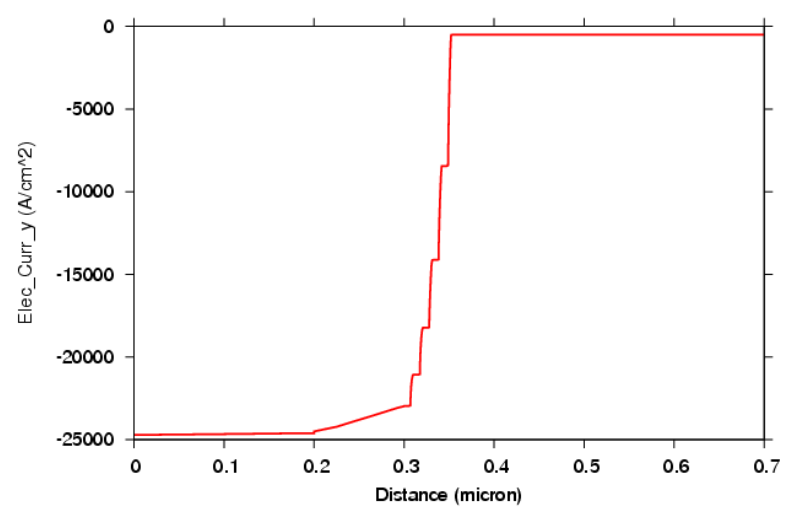

Fig. 10: Vertical profile of the electron current density.

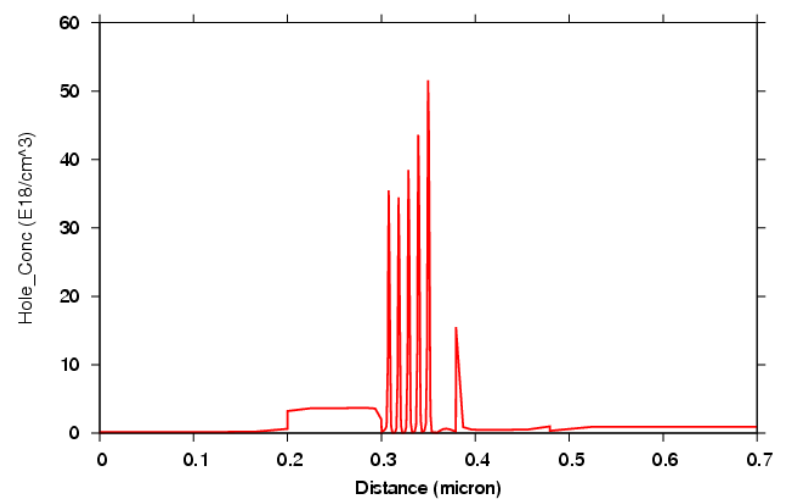

Fig. 7: Vertical profile of the hole density.

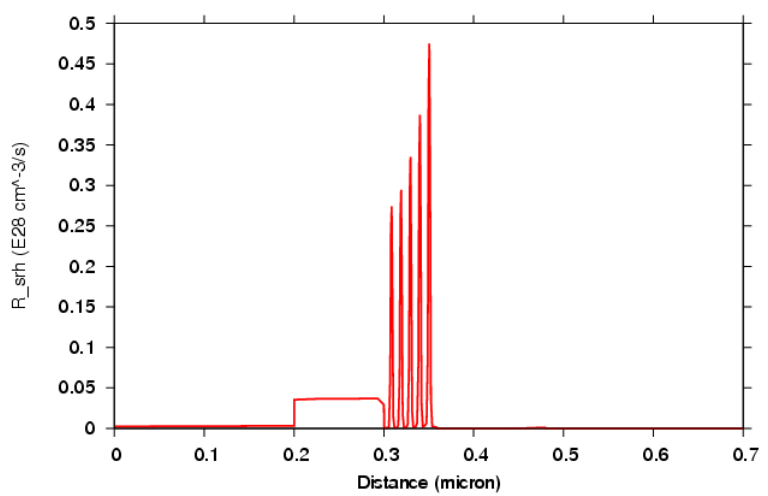

Fig. 9: Vertical profile of the SRH recombination rate.

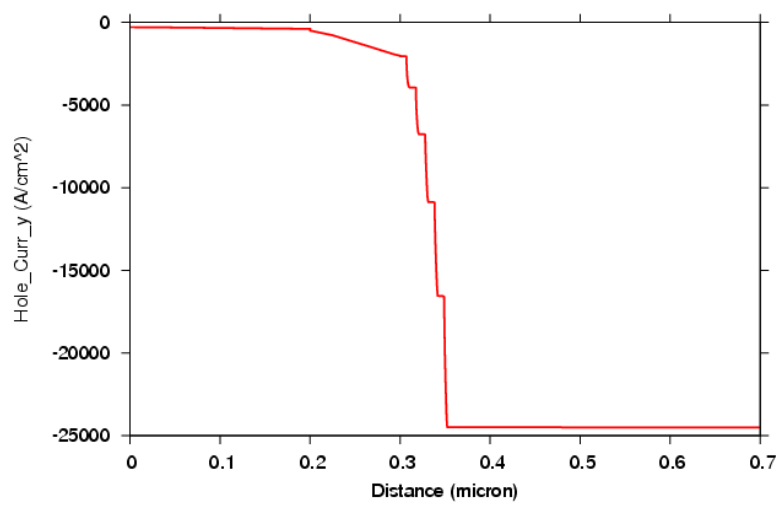

Fig. 11: Vertical profile of the hole current density. 
In the following, we evaluate the laser performance as function of emission wavelength. The QW indium composition is varied in the simulation to cover the experimental wavelength range. Figure 12 shows the resulting threshold current density in comparison to the measurement. The good agreement has been achieved by fine-tuning the SRH lifetime and the renormalization parameter, which are both unknown for our device. The simulation reproduces the strong rise of the threshold current with shorter wavelength and it enables us to now investigate the internal reasons for this behavior.

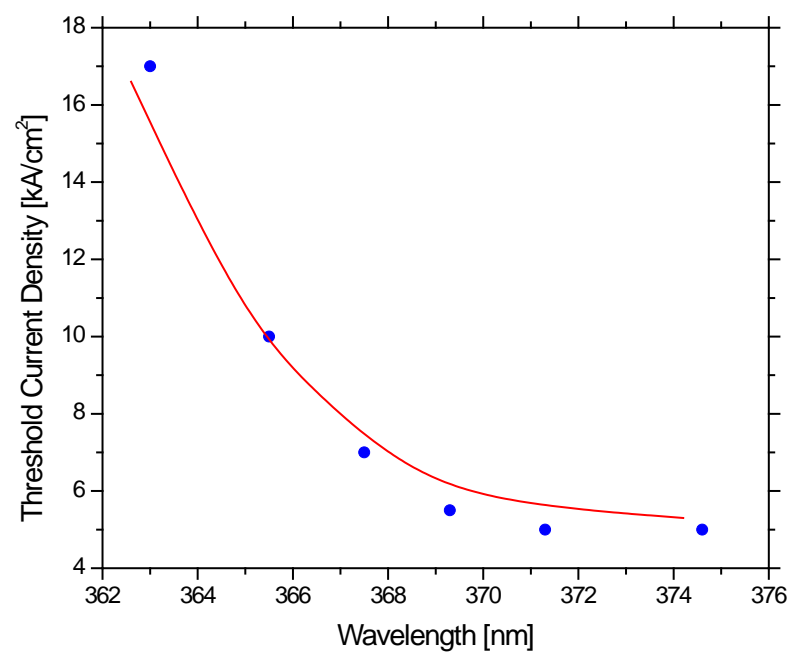

Fig. 12: Threshold current density vs. emission wavelength (dots - measurement, line - simulation).

We identify mainly two reasons for the increased threshold current. The first reason is the strongly rising band-tail absorption with shorter wavelength (higher photon energy, cf. Fig. 1). The corresponding modal absorption for our device is plotted in Fig. 13. The second reason is the enhanced hole leakage due to the more shallow quantum wells at shorter wavelength. The hole leakage as function of wavelength is plotted in Fig. 14 and it shows an increased wavelength sensitivity below $370 \mathrm{~nm}$, which seems to trigger the increased wavelength sensitivity of the threshold current in Fig. 12.

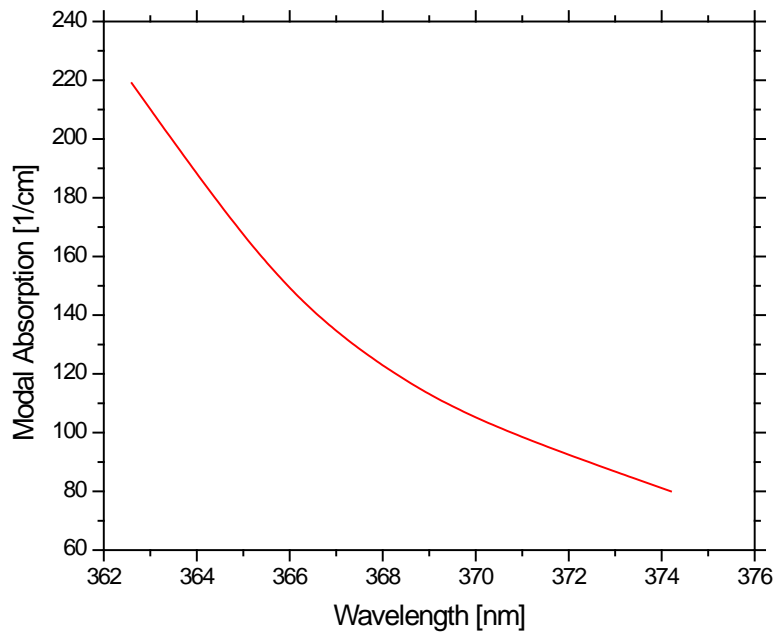

Fig. 13: Modal absorption as function of wavelength.

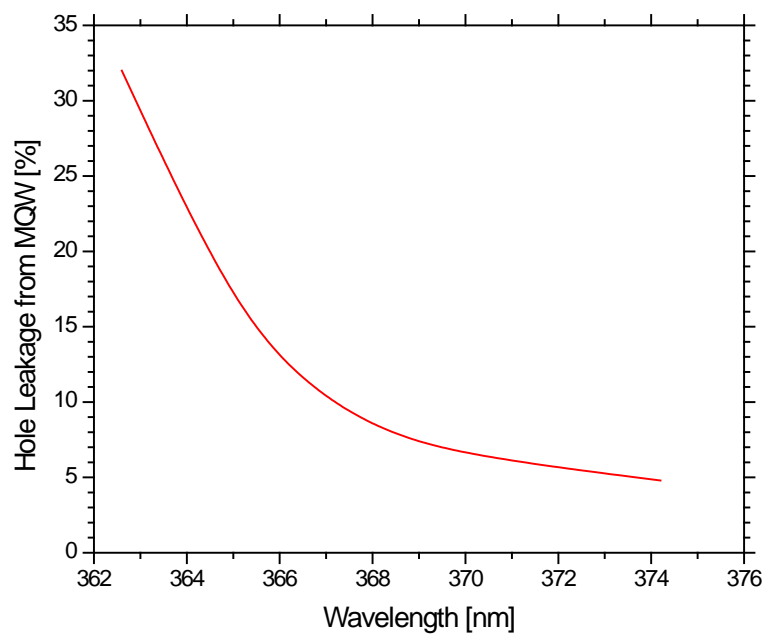

Fig. 14: Hole leakage as function of wavelength. 


\section{SUMMARY}

Employing advanced laser simulation, we have revealed the internal physical mechanisms that cause the experimentally observed super-linear rise in threshold current of GaN-based UV lasers with shorter wavelength.

\section{REFERENCES}

${ }^{1}$ Michael Kneissl, David W. Treat, Mark Teepe, Naoko Miyashita, and Noble M. Johnson, "Continuous-wave operation of ultraviolet InGaN/InAlGaN multiple-quantumwell laser diodes,” Appl. Phys. Lett. 82, 2386 - 2389, 2003.

${ }^{2}$ LASTIP by Crosslight Software, Inc. (www.crosslight.com).

${ }^{3}$ J. Piprek, Semiconductor Optoelectronic Devices: Introduction to Physics and Simulation, Academic Press, San Diego, 2003.

${ }^{4}$ I. Vurgaftman and J. R. Meyer, “Electron Bandstructure Parameters,” Ch. 2 in: Nitride Semiconductor Devices: Principles and Simulation, ed. J. Piprek, 13 - 37, Wiley-VCH, Weinheim, 2007.

${ }^{5}$ F. Bernardini, "Spontaneous and Piezoelectric Polarization: Basic theory vs. Practical Recipes,” Ch. 3 in: Nitride Semiconductor Devices: Principles and Simulation, ed. J. Piprek, 49 - 67, Wiley-VCH, Weinheim, 2007.

${ }^{6}$ S. L. Chuang and C. S. Chang, “A band-structure model of strained quantum-well wurtzite semiconductors,” Semicond. Sci. Technol. 12, 252-263, 1997.

${ }^{7}$ 0. Ambacher, W. Rieger, P. Ansmann, H. Angerer, T.D. Moustakas and M. Stutzmann, „Sub-Bandgap Absorption Of Gallium Nitride Determined By Photothermal Deflection Spectroscopy,” Solid State Comm. 97, 365-370, 1996.

${ }^{8}$ F. Omnes, N. Marenco, B. Beaumont, Ph. de Mierry, E. Monroy, F. Calle, and E. Munoz; "Metalorganic vapor-phase epitaxy-grown AlGaN materials for visible-blind ultraviolet photodetector applications,” J. Appl. Phys. 86, 52865292, 1999.

${ }^{9}$ M. Kuramoto, C. Sasaoka, N. Futagawa, M. Nido, and A. A. Yamaguchi, "Reduction of Internal Loss and Threshold Current in a Laser Diode with a Ridge by Selective Re-Growth (RiS-LD),” phys. stat. sol. (a) 192, 329-334, 2002.

${ }^{10}$ M. Büttner and H. Wenzel, unpublished.

${ }^{11}$ R. Goldhahn, C. Buchheim, P. Schley, A. T. Winzer, and H. Wenzel, “Optical Constants of Bulk Nitrides,” Ch. 5 in: Nitride Semiconductor Devices: Principles and Simulation, ed. J. Piprek, 95 - 114, Wiley-VCH, Weinheim, 2007. 